Anales de Geografía de la Universidad Complutense ISSN: 0211-9803

http://dx.doi.org/10.5209/AGUC.57728

\title{
Análisis de los cambios socioambientales en el Morro de Moravia en Medellín (Antioquia-Colombia)
}

\author{
Yanneth Bibiana Daza Vargas ${ }^{1}$; Sonia Yamile Rodríguez Murcia ${ }^{2}$; \\ Gloria Yaneth Florez Yepes ${ }^{3}$; Jorge Montoya Restrepo ${ }^{4}$ \\ Recibido: 18 de octubre del 2016 / Enviado a evaluar: 28 de febrero del 2017 / Aceptado: 24 de mayo del 2017
}

Resumen. Para la investigación de los cambios socioambietales del "Morro Moravia" Se utilizó la metodología de investigación mixta con enfoque empírico analítico. Las etapas de desarrollo comprenden: un análisis multitemporal y un análisis de las percepciones frente a la transformación socioambiental de un sitio que inició como un botadero de basura y tuvo un posterior reasentamiento. Para el análisis multitemporal se utilizaron imágenes de google earth de los años 2005, 2008, 2011, 2013, y 2015, las cuales fueron debidamente georreferenciadas mediante la identificación de puntos de control. Igualmente se realizó la sistematización y revisión de las intervenciones llevadas a cabo en el marco de varios proyectos y estudios desarrollados en el sitio, con el fin de detectar los cambios ocurridos con su implementación, así como la medición de la percepción que tiene la comunidad frente a dichas intervenciones a partir de la utilización de encuestas.

Palabras claves: Transformación socioambiental; análisis multitemporal; botadero.

\section{[en] Analysis of socio-environmental changes in the Morro de Moravia in Medellín (Antioquia-Colombia)}

\begin{abstract}
For the investigation of Socio-environmental changes of "Morro Moravia" mixed research methodology was used with analytical empirical approach. Development stages comprises: a multitemporal analysis and an analysis of the perceptions of the social and environmental transformation of a site that began as a garbage dump and had a subsequent resettlement. For the multitemporal analysis we used images of google earth of the years 2005, 2008, 2011, 2013, and 2015 which were properly georeferenced by the identification of control points. It was also carried out the systematization and review of the interventions carried out in the framework of several projects developed in the site, in order
\end{abstract}

\footnotetext{
Universidad de Antioquia (Colombia).

Universidad de Santo Tomás (Colombia).

Universidad de Manizales (Colombia).

E-mail: gflorez@umanizales.edu.co

4 Universidad de Antioquia (Colombia) y UNESCOsost-Colombia.
} 
to detect the changes that occurred with its implementation, as well as the measurement of the perception that the community has against these Interventions based on the use of surveys

Key words: Social and environmental transformation, indicator; waste disposal space.

\section{[fr] Analyse des changements socio-environnementaux dans le Morro de Moravia à Medellín (Antioquia-Colombie)}

Résumé. Pour l'enquête de la transformation socio-environnementale méthodologie de recherche mixte « Morro de Moravie » a été utilisé à l'approche empirique analytique. les étapes de développement comprend: une analyse multitemporelle et une analyse des perceptions de la transformation sociale et environnementale d'un site qui a commencé comme un dépotoir d'ordures et avait une réinstallation ultérieure pour multitemporelle analyse les images de Google Earth pour 2005 ont été utilisés 2008, 2011, 2013 et 2015, ils ont été dûment géoréférencées en identifiant les points de contrôle. Aussi a eu lieu la systématisation et l'examen des interventions menées dans le cadre de plusieurs projets développés sur le site, afin de détecter des modifications à leur mise en œuvre et la mesure de la perception de la communauté contre une telle les interventions de l'utilisation d'enquêtes.

Mots clés: Transformation socio-environnementale; analyse multitemporelle; décharge

Cómo citar. Daza Vargas, Y.B., Rodríguez Murcia, S.Y., Florez Yepes, G.Y. y Montoya Restrepo, J. (2017): Análisis de los cambios socioambientales en el Morro de Moravia en Medellín (AntioquiaColombia). Anales de Geografía de la Universidad Complutense, 37(2), 325-348.

Sumario. 1. Introducción. 2. Metodología. 2.1. Retrospectiva de los cambios socioambientales en el Morro de Moravia. 2.1.1. Análisis multitemporal. 2.2. Percepción frente a las intervenciones socioambientales. 3. Resultados. 3.1. Retrospectiva de cambios socioambientales identificados en el Morro de Moravia. 3.2. Percepción de la Comunidad de Moravia frente a las intervenciones de transformación socioambiental realizadas en el Morro. 3.3. Discusión y análisis de resultados. 4. Conclusiones. 5. Bibliografía.

\section{Introducción}

Colombia ha sufrido una serie de impactos ocasionados por el crecimiento desmedido de la población; en materia ambiental es importante analizar los procesos urbanos que son causa y consecuencia de condiciones socioeconómicas; según Corellano (2014), el medio ambiente de las ciudades es el resultado de la intensa acción humana, muchas veces prolongada y multiforme, sobre un espacio físico reducido que tiene como resultado unas determinadas condiciones para la vida.

En diferentes etapas de la historia del país, las poblaciones que experimentan desplazamiento enfrentan condiciones de pobreza extrema, sin techo y sin alimento, estas personas se ven enfrentadas a procesos de invasión de zonas que no fueron inicialmente destinadas para viviendas, se generan conflictos, inseguridad, riesgo tanto social como ambiental,

Para el caso de investigación, las familias involucradas encontraron en el Morro de Moravia la solución inmediata para satisfacer el hambre en condiciones sanitarias 
inaceptables, y los materiales y elementos que les sirvieron para construir viviendas e iniciar una nueva vida.

El proceso socioambiental implica un cambio trascendental, nuevas condiciones de vida para los interesados, la dicotomía entre abandonar lo que consiguieron e involucrarse en programas sociales y ambientales que para muchos representan oportunidades pero para otros constituyen una amenaza a lo que con esfuerzo y dolor encontraron.

En las últimas décadas, la sociedad moderna se ha caracterizado por hacer menos evidentes y necesarias las relaciones de proximidad de las comunidades con el territorio en el cual habitan.

Ascher (2004, citado en Morató et al, 2012) plantea que el pensamiento moderno introduce tres modos de interacción que originan, en parte, la crisis actual: la individualización o el dominio del interés particular sobre el colectivo; la racionalización de la visión social frente a una visión mítica o espiritual de sociedades pre modernas y la marcada diferenciación social producto de la especialización de funciones propias del sistema de organización y funcionamiento del sistema productivo industrial.

Garrido (2010) retoma un planteamiento posterior que Ascher expuso en su libro "diario de un hipermoderno" publicado en 2009; en el que se diferencia la "modernidad" de la "hipermodernidad", y se resalta que esta última es el resultado de una nueva estructura de sociedad, en donde cada individuo modifica las relaciones con la comunidad y va adoptando una personalidad distinta según las circunstancias, su racionalidad depende del contexto y las relaciones sociales dependen de las circunstancias.

Para Minotta (2012) la participación ciudadana es un eje de la gestión ambiental, que se da a través de procesos sociales y culturales, y va más allá de los mecanismos institucionales. Este planteamiento se evidenció en Moravia donde las personas que se instalaron se adaptaron a las condiciones sociales y ambientales del lugar, satisfaciendo la necesidad básica de vivienda sin tener en cuenta las condiciones de riesgo ambiental no mitigable a las que podían estar expuestos.

Para Angel (2003), en Colombia se visualiza la realidad de un desarrollo que no se ajusta a la potencialidad de los recursos, por lo tanto las condiciones de los mercados dejan como resultado la crisis, es así que la sociedad empieza a organizarse de una nueva forma en la que se evidencia la crisis ambiental planteada desde la forma como ha sido planteado el desarrollo urbano y menciona la inquietud de incitar a futuros investigadores a estudiar la ciudad desde las interconexiones regionales como centros de transformación ecosistémica; "de la que todos somos responsables, no solo para lograr la supervivencia y el desarrollo de la especie, sino igualmente para organizar una cultura que encuentre su ubicación y su equilibrio con el resto del sistema vivo" (Ángel, 2003, p.116)

A nivel local, nacional e internacional se han referenciado casos similares al Morro de Moravia, uno de ellos es el "vertedero de La Chureca (Nicaragua)", donde la existencia de un vertedero no controlado ofreció riesgos de contaminación e 
insalubridad por 40 años, tanto para la población como para el medio ambiente (Agencia Española de Cooperación \& Grupo Tragsa, 2012). "Situación agudizada después del paso del Huracán Mitch en 1998, cuando la cota de agua del lago que limita el vertedero, se elevó inundando gran parte de éste" (Agencia Española de Cooperación \& Grupo Tragsa, 2012, p.34). Después de esto se iniciaron acciones encaminadas al sellado del vertedero, a fin de evitar los riesgos asociados a la contaminación de la zona.

Otro caso de interés como proceso de transformación ambiental es "La Restauración ambiental y paisajística de un vertedero incontrolado en Castellón (Este de España)". En el cual se dispusieron por aproximadamente 20 años residuos sólidos urbanos y restos inorgánicos, que alteraron la vegetación, la fauna, los acuíferos, los usos del suelo, así como la calidad ambiental y paisajística del entorno (Fabregat et al, 2011) lo que aceleró su clausura, restauración y valoración ambiental y paisajística, trazando un cambio de uso del suelo.

Otra experiencia a destacar es Puerto Lempira (Honduras) donde se ubica la Laguna Caratasca la cual hace parte de un sistema de humedales costeros declarado Reserva Biológica. A las orillas de la laguna se generó un crecimiento urbano acelerado y no planificado como muchas zonas del mundo conformándose una comunidad urbana de 15.000 habitantes, crecimiento poblacional acompañado de un aumento en la generación de residuos de todo tipo, que eran vertidos directamente sobre el suelo, quemados a cielo abierto o arrojados al lago, que también era receptor de los residuos de navegación (carburantes, aceites y plásticos). En el 2006 la comunidad impulso una iniciativa consistente en prestar el servicio de transporte y clasificación de desechos a fin de limpiar el núcleo urbano y la laguna (ONU-Habitat, 2012).

Las experiencias referenciadas anteriormente, tienen elementos en común con la evidenciada en El Morro de Moravia, en todos hay una problemática socio ambiental generada por un crecimiento urbano no planificado y como lo afirma Salazar (2003), “ en los estudios de áreas urbanas degradadas deben abordarse grandes retos en lo relacionado con fortalecer el capital social y humano de la comunidad; además de suscitar la articulación y gestión de los actores locales que lleven a evaluar la sostenibilidad" (p.90) de las intervenciones realizadas.

En esta investigación se realiza una evaluación socioambiental de la transformación que ha experimentado el Morro de Moravia en la ciudad de Medellín; este lugar es catalogado como una zona de riesgo debido a que el suelo fue generado de forma antropogénica producto de la acumulación de residuos sólidos de toda la ciudad y referenciado como "botadero de basura", luego de ser el lugar de disposición final de los residuos se fue poblando progresivamente por diferentes grupos de personas, familias que llegaban a la zona en condición de desplazamiento de diferentes lugares del país, lo que llevó a instituciones y organizaciones a centrar su interés en cambiar las condiciones de vida de los moradores del Morro. 


\section{Metodología}

\subsection{Retrospectiva de los cambios socioambientales en el Morro de Moravia}

Para el análisis de los cambios socioambientales identificados en el Morro de Moravia se tuvo en cuenta un momento de retrospectiva, uno de cambios espaciales, y finalmente uno de percepciones. En el primero, se analizó diferente información histórica, estudios e intervenciones que se han realizado en el proceso de transformación del morro a través del tiempo, las cuales han sido tanto sociales como de infraestructura física, en el segundo se utilizaron herramientas cartográficas para realizar un análisis multitemporal, con el fin de tener una visión del cambio a través del tiempo, teniendo como referente una escala igual para diferentes momentos de la evolución de los proyectos o intervenciones ejecutadas en el área de estudio, y en el tercero se abordó a la comunidad con el fin de conocer sus percepciones frente a los cambios ocurridos en la zona de estudio.

\subsubsection{Análisis multitemporal}

Con el fin de evidenciar de manera gráfica, en una escala constante, los cambios referenciados por sensores remotos y con las imágenes de dominio público, se proyectó el comportamiento de la ocupación de áreas.

Los mapas fueron trabajados en una escala 1:600. La metodología se basó en un análisis comparativo de imágenes de satélite capturadas de la plataforma de Google Earth en diferentes épocas de tiempo, que fueron georreferenciadas en el sistema de coordenadas Magna - Colombia - Bogotá. Dicho análisis comparativo necesitó que se causaran las siguientes etapas:

1. Ubicar la zona de estudio en el visor del software ArcGIS.

2. Cargar la imagen de Google Earth de la primera época que se iba a estudiar.

3. Georreferenciar la imagen mediante la identificación de puntos de control en ambas imágenes.

4. Trazar el límite de la zona de estudio.

5. Trazas las diferentes coberturas de uso del suelo y calcular sus respectivas áreas de ocupación.

6. Repetir el procedimiento para las demás imágenes de satélite.

A continuación se relacionan las imágenes correspondientes a la generación de cartografía para apoyar el proyecto de investigación. Fueron halladas imágenes de los años 2005, 2008, 2011, 2013 (abril), 2013 (julio) y 2015. 


\subsection{Percepción frente a las intervenciones socioambientales}

Para conocer la percepción que tienen las personas de Moravia acerca de las intervenciones socioambientales llevadas a cabo en el morro, se realizó una encuesta. Inicialmente se efectuó una prueba piloto, luego se estableció la muestra, y después se procedió a su aplicación en campo.

\section{- Prueba piloto}

En julio de 2015, se aplicó un piloto con líderes y lideresas del barrio de Moravia que permitió establecer las siguientes consideraciones:

1. Los líderes y lideresas de Moravia demuestran tener conocimiento de las intervenciones ejecutadas en este sitio.

2. Algunas personas sienten temor al suministrar su identificación

3. Dada la complejidad del sitio, porque aún no termina el proceso de reasentamiento de las familias, se debe procurar llegar a por lo menos el $50 \%$ de las que siguen establecidas en este lugar declarado de alto riesgo.

\section{- Ajustes a la técnica con base en los resultados de la prueba piloto (premuestreo)}

De acuerdo con los resultados de la prueba piloto se ajustó la encuesta teniendo en cuenta que:

1. La información de edad no es relevante para la investigación propia que se adelanta, no obstante, presenta utilidad para las entidades que han colaborado con la investigación; motivo por el cual se deja como parte de la encuesta.

2. Un alto porcentaje de la población se encuentra en estrato 1 y 2 , y carecen de computador, evidenciándose que en su gran mayoría no tienen correo electrónico por tanto se suprime de la encuesta este ítem.

3. Se considera necesario incorporar otras preguntas que den cuenta de aspectos sociales y de los procesos participativos que se han adelantado allí.

\section{- Determinación de la muestra para la aplicación de la encuesta}

Para el cálculo del tamaño de la muestra se utilizó la siguiente formula:

$$
n=\frac{Z^{2} p q N}{\cdots ?-?}
$$

El tamaño de la muestra fue calculada con base en los siguientes datos:

$\mathbf{n}=$ Tamaño de la muestra

$\mathbf{p}=$ Probabilidad de aceptación

$\mathbf{q}=$ Probabilidad de rechazo (1-p)

$\mathbf{Z}=$ Valor de la distribución normal (1,96 para un nivel de confianza del 95\%)

$\mathbf{E}=$ Error máximo permitido. (Se asumió del 8\%) 
En este caso se conoció el tamaño de la muestra estando el universo conformado por 600 familias con un margen de error $+-8 \%$; operando con un coeficiente de confianza del 95\%, teniendo en cuenta lo anterior se obtuvo que: $\mathbf{n}=\mathbf{1 1 7}$ familias

\section{- Aplicación de la encuesta}

Se aplicó la encuesta a 117 de las familias que habitaron y habitan el morro de Moravia, así como a líderes y lideresas del barrio. Responsable de aplicación de la técnica: Las responsables de la aplicación de la técnica fueron las maestrantes líderes de la investigación.

\section{- Tiempo de aplicación de la técnica}

La encuesta se aplicó a la población asentada en el morro de Moravia y reasentados en el mismo barrio. La aplicación de la encuesta tuvo una duración de tres (3) días.

\section{- Lugar de aplicación}

La aplicación de la encuesta se llevó a cabo en el sector de Moravia, en diferentes jornadas y sitios de acuerdo con la población objetivo:

Jornada 1: Con población reasentada en edificios perimetrales al barrio: Álamos I y II. Jornada 2: Población que actualmente habita el Morro de Moravia

Jornada 3: Con líderes y lideresas del Barrio en las diferentes reuniones convocadas con las organizaciones comunitarias.

Se contó con un formato de registro de las viviendas encuestadas (Ver ¡Error! No se encuentra el origen de la referencia.), el cual permitió consolidar una base de datos de las personas que accedieron a responder la encuesta, a la vez que sirvió como evidencia del consentimiento informado.

\section{Resultados}

\subsection{Retrospectiva de cambios socioambientales identificados en el Morro de Moravia}

En la Tabla 3 se presenta una restrospectiva cronológica en función de las intervenciones socioambientales implementadas en el Morro de Moravia, así como una compilación de las acciones, los cambios, las intervenciones que han tenido lugar en este sitio, a partir del año 1969; momento en el cual se inició la disposición de residuos a cielo abierto en el área de interés de esta investigación. Esta retrospectiva permite evidenciar, momentos clave en donde existe una transición en el proceso antropogénico. 
Tabla 1. Restrospectiva cronológica en función de las intervenciones socioambientales en el Morro de Moravia

\begin{tabular}{|c|c|c|c|c|c|c|c|c|c|c|c|}
\hline \multirow{4}{*}{ sockul } & & 1969 & 1972 & 19978 & 1992 & 1963 & 1990 & 2000 & 2004 & 2005 & 2006 \\
\hline & Economia & & 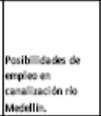 & 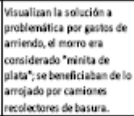 & 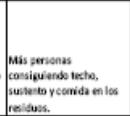 & 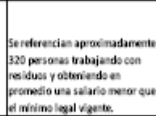 & & & & & \\
\hline & 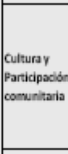 & & & & 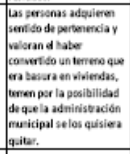 & & 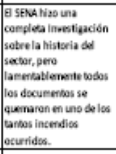 & & & 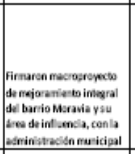 & \\
\hline & Pobtución & & 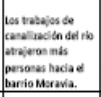 & 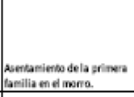 & 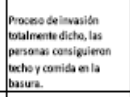 & 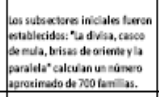 & & 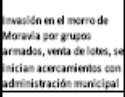 & 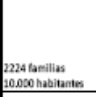 & $\begin{array}{l}\text { Toul berio vowia: } \\
\text { 37643 }\end{array}$ & 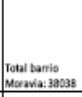 \\
\hline \multirow{5}{*}{ aмaеsта2 } & 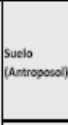 & 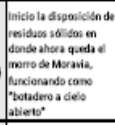 & & & & 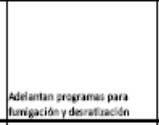 & & & 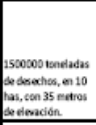 & & \\
\hline & Aine & & & & & & & & & 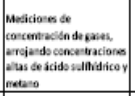 & \\
\hline & Funs & & & & & 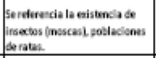 & & & & & \\
\hline & Vegertacion & & & & & & & & & & \\
\hline & Agua & & 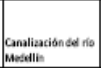 & & 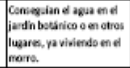 & & & & & & \\
\hline
\end{tabular}

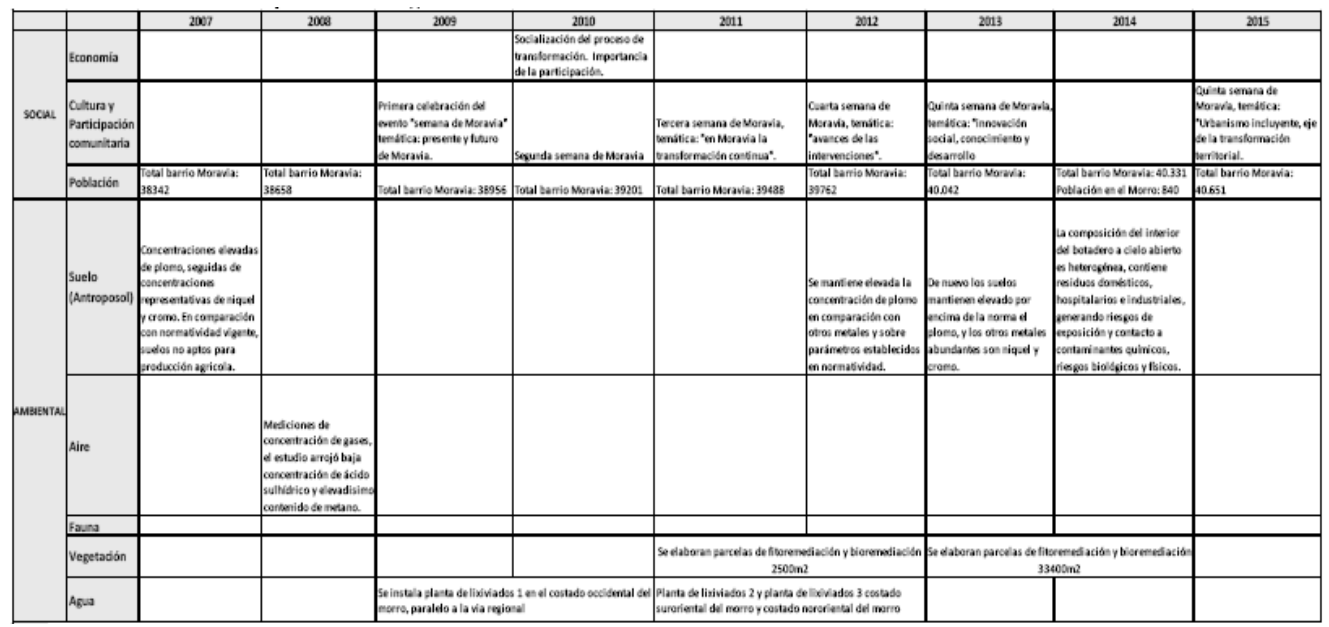

Fuente: Elaboración propia a partir de proyectos consultados.

En 1978, aproximadamente una década después de que se iniciara el botadero a cielo abierto; ya se evidenciaba la posibilidad de establecer viviendas en el Morro de Moravia. En el 2004 mediante cálculos aritméticos la densidad estaría en 7 personas/metro cuadrado, teniendo en cuenta que vivían en el morro alrededor de diez mil personas; y al analizar las características físicas del terreno se tiene la referencia de una elevación de 35 metros. A partir de esta fecha se tienen referenciadas las 
intervenciones y la reubicación de personas a partir de los proyectos para contrarrestar la problemática social y ambiental en el área.

La principal razón de la ejecución de proyectos respondió a la necesidad de disminuir la vulnerabilidad ante el riesgo ambiental que representa la existencia de metales pesados y gases que pongan en peligro la salud y la integridad de las personas.

A partir del 2004 y en los siguientes años, se puede observar con ayuda de la matriz que se presenta en la tabla 3 , que existieron unos procesos de carácter social y ambiental, a partir de los cuales se presenta una transformación integrando soluciones ambientales como fitorremediación y biorremediación con la participación de actores de la comunidad y la asesoría, apoyo y coordinación de instituciones diferentes, pero es posible analizar también que existen intervenciones aisladas.

\section{a) Análisis multitemporal}

Se logró establecer una serie temporal que permite observar el cambio a través de los años en el área de estudio.

Figura 1. Comparativo general $2005-2011$
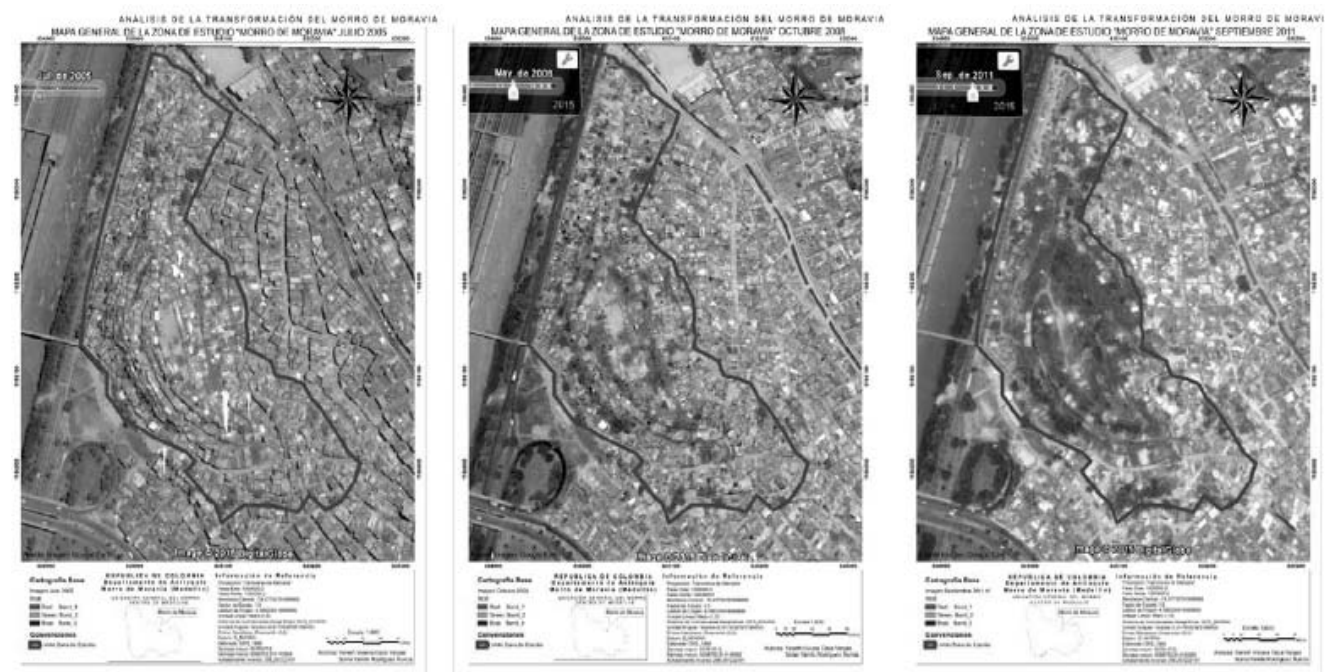

Fuente: Elaboración propia.

Las Figuras 1 y 2 recogen una comparativa general 2013 - 2015, donde muestran el proceso de transformación. La imagen del año 2005 evidencia una alta densidad poblacional como puede verse en los polígonos que demarcan el área de estudio. 
Figura 2. Comparativo general $2013-2015$
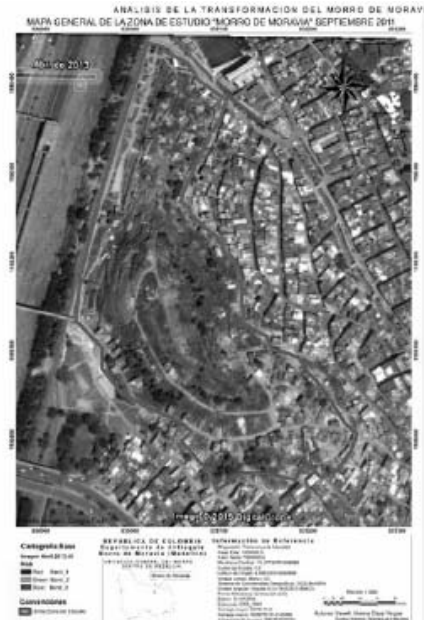
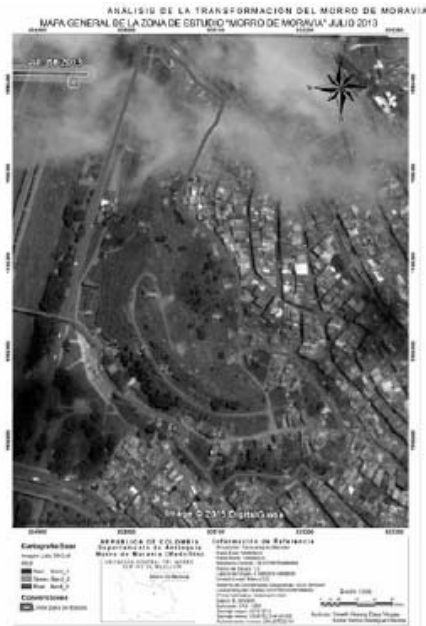

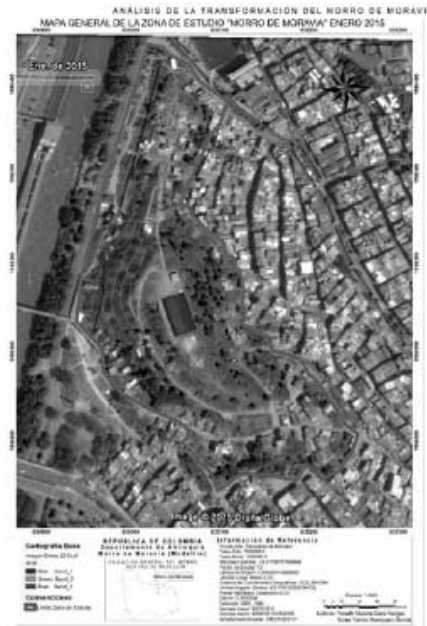

Fuente: Elaboración propia.

La imagen del 2008 que corresponde a la segunda imagen en la figura 1, presenta unos pequeños relictos verdes dispersos que van aumentando a medida que se van reubicando las familias como se observa en las imágenes correspondientes a los años 2011 y 2013. La imagen correspondiente a 2015 que corresponde a la última imagen de la figura 2, muestra cómo los jardines de fitoremediación y biorremediación ocupan algunas zonas de las viviendas que han sido reubicadas.

Figura 3. Comparativo uso del suelo $2005-2011$
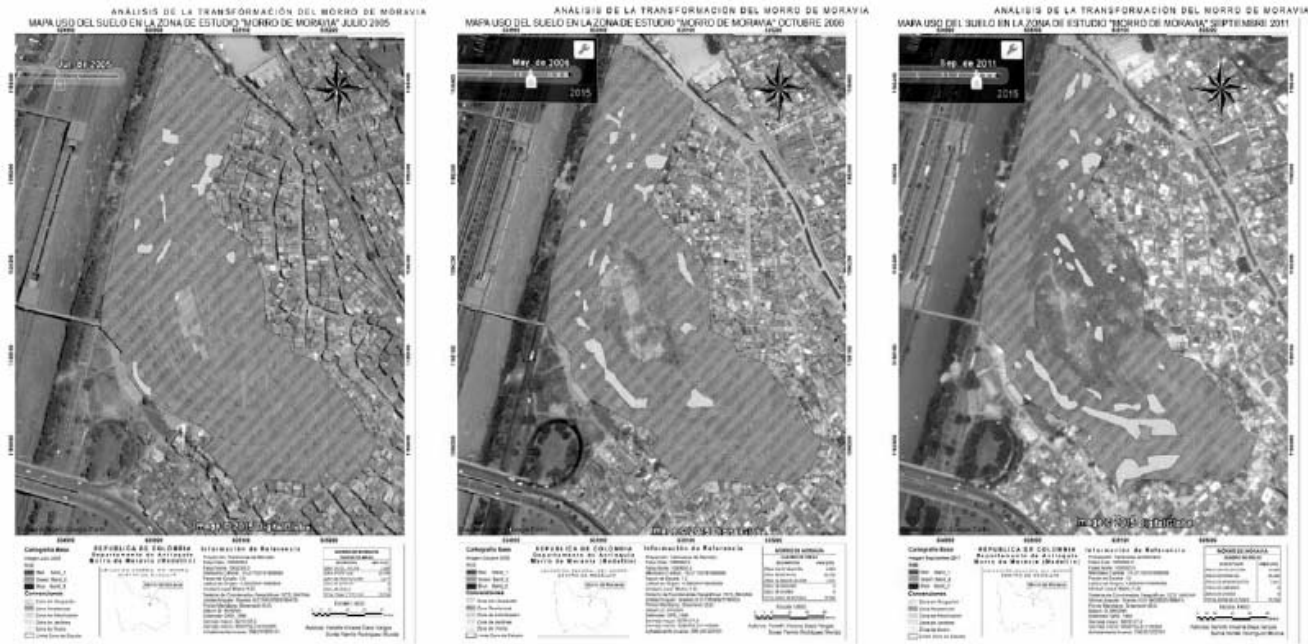

Fuente: Elaboración propia. 
Figura 4. Comparativo uso del suelo $2013-2015$
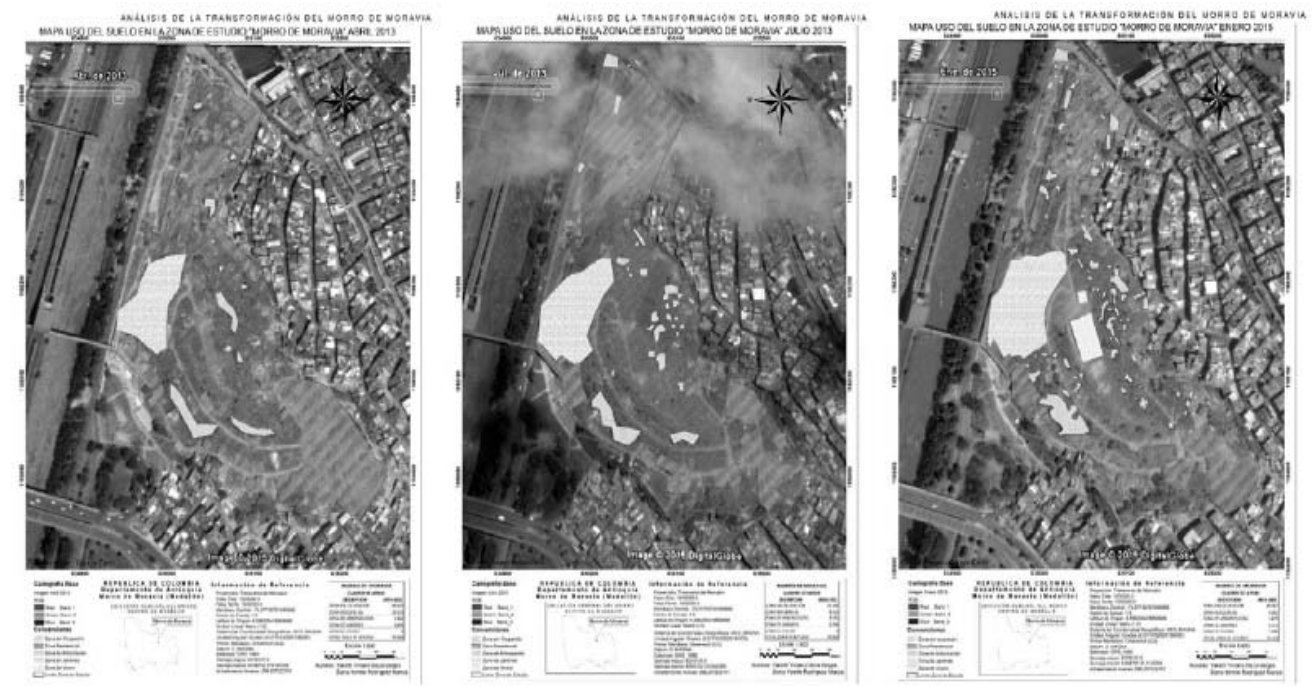

Fuente: Elaboración propia.

En las Figuras 3 y 4, establecen una comparativa del suelo 2013 - 2015, muestra de manera cronológica la transformación de la zona de estudio: La zona sin ocupación (sin color), la zona residencial (en color naranja), la zona de arborización (en color verde), la zona de jardines (en color violeta) y la zona de vivero (en color verde claro).

\section{b) Variación en usos del suelo en el Morro de Moravia}

Con los datos obtenidos mediante la digitalización cartográfica de las imágenes digitales consultadas, se obtuvieron representaciones anuales para el uso del suelo por medio de software ArcGIS se calculó la variación de las áreas en la través del tiempo.

En la Tabla 2, comparativo de áreas con usos específicos en el morro de Moravia 2005 - 2015, se relacionan los valores que permitirán calcular la transformación en porcentajes de ocupación de áreas al momento de alimentar los indicadores formulados para la investigación. 
Tabla 2. Comparativo de áreas con usos específicos en el morro de Moravia 2005 - 2015

\begin{tabular}{|c|c|c|c|c|c|c|}
\hline \multirow{2}{*}{ Descripción } & 2005 & 2008 & 2011 & 2013-1 & 2013-2 & 2015 \\
\hline & \multicolumn{6}{|c|}{ Área $\left(\mathbf{m}^{2}\right)$} \\
\hline Zona sin ocupación & 1.684 & 6.813 & 19.449 & 48.633 & 52.764 & 49.962 \\
\hline Zona residencial & 67.197 & 60.220 & 45.248 & 15.633 & 9.516 & 9.265 \\
\hline $\begin{array}{c}\text { Zona de } \\
\text { arborización }\end{array}$ & 1.677 & 3.525 & 5.861 & 1.862 & 2.574 & 3.479 \\
\hline Zona de jardines & 0 & 0 & 0 & 4.430 & 5.704 & 6.552 \\
\hline Zona de vivero & 0 & 0 & 0 & 0 & 0 & 1.300 \\
\hline $\begin{array}{l}\text { Total zona de } \\
\text { estudio. }\end{array}$ & 70.558 & 70.558 & 70.558 & 70.558 & 70.558 & 70.558 \\
\hline
\end{tabular}

Fuente: Elaboración propia

Los datos demográficos encontrados puntualmente sobre el morro, con fuente de datos oficial, se obtuvieron del año 2014, obtenidos del "Plan de habilitación ambiental del morro de Moravia", cuya fuente fue ISVIMED (Instituto social de vivienda y hábitat de Medellín). En donde se tenía referenciada una población de 840 habitantes distribuidos en 127 familias.

Tabla 3. Población del Morro de Moravia (2014).

\begin{tabular}{|c|c|}
\hline \multicolumn{2}{|c|}{ Población Morro de Moravia 2014 } \\
\hline Rango de edad & Cantidad \\
\hline menos de 5 & 108 \\
\hline 6 a 12 & 116 \\
\hline 13 a 18 & 107 \\
\hline 18 a 29 & 233 \\
\hline 30 a 60 & 232 \\
\hline más de 60 & 44 \\
\hline Total & 840 \\
\hline
\end{tabular}

Fuente: Plan de Habilitación Ambiental de Moravia (2014). 


\subsection{Percepción de la Comunidad de Moravia frente a las intervenciones de transformación socioambiental realizadas en el Morro}

Mediante una encuesta aplicada en el mes de julio de 2015 se buscó conocer la percepción de la comunidad acerca de las intervenciones de transformación socioambiental llevadas a cabo en el Morro de Moravia y al mismo tiempo conocer como ha sido la participación comunitaria a través del tiempo, la opinión de la población reasentada y la que habita el morro de Moravia frente al mejoramiento en la calidad de vida e indagar sobre su percepción frente a la difusión y divulgación del proceso.

Se encuestaron en total 117 familias, de las cuales 87 correspondieron a familias reasentadas, y 30 a familias que continúan viviendo en el morro de Moravia. La distribución del número de encuestas por sector se estableció considerando el número de viviendas (o familias) por categoría (reasentadas y no reasentadas), con el fin de realizar comparaciones coherentes acordes con la muestra establecida (Ver Tabla 4).

Tabla 4. Distribución de viviendas a encuestar por categoría

\begin{tabular}{|c|c|c|c|}
\hline Categoría & $\begin{array}{c}\# \\
\text { Viviendas }\end{array}$ & $\begin{array}{c}\text { \% Categoría/Total } \\
\text { de viviendas }\end{array}$ & $\begin{array}{c}\text { \% Viviendas } \\
\text { encuestadas }\end{array}$ \\
\hline $\begin{array}{c}\text { Reasentados (Edificios } \\
\text { Álamos 1 y 2, La } \\
\text { Herradura) }\end{array}$ & 447 & 75 & 87 \\
\hline Morro & 153 & 25 & 30 \\
\hline Total & $\mathbf{6 0 0}$ & $\mathbf{1 0 0}$ & $\mathbf{1 1 7}$ \\
\hline
\end{tabular}

Fuente: Elaboración propia con información de número de viviendas (apartamentos) de reasentados entregada por Líder Rosa Ríos y Neira Agudelo.

La información recopilada fue organizada y tabulada. Las gráficas $1-8$ muestran la percepción que tiene la población reasentada y la no reasentada frente a las intervenciones socioambientales realizadas y su incidencia en el mejoramiento de la calidad de vida de los habitantes del barrio.

La Familias con conocimiento acerca de las intervenciones socioambientales realizadas en el morro de Moravia a Julio de 2015, el 93\% de los encuestados informaron conocer sobre las intervenciones, un 7\% omitió responder, objetando que si habían visto cambios y que había mucho jardín, pero que no conocían. 
Gráfica 1. Familias con conocimiento acerca de las intervenciones socioambientales realizadas en el morro de Moravia a Julio de 2015.

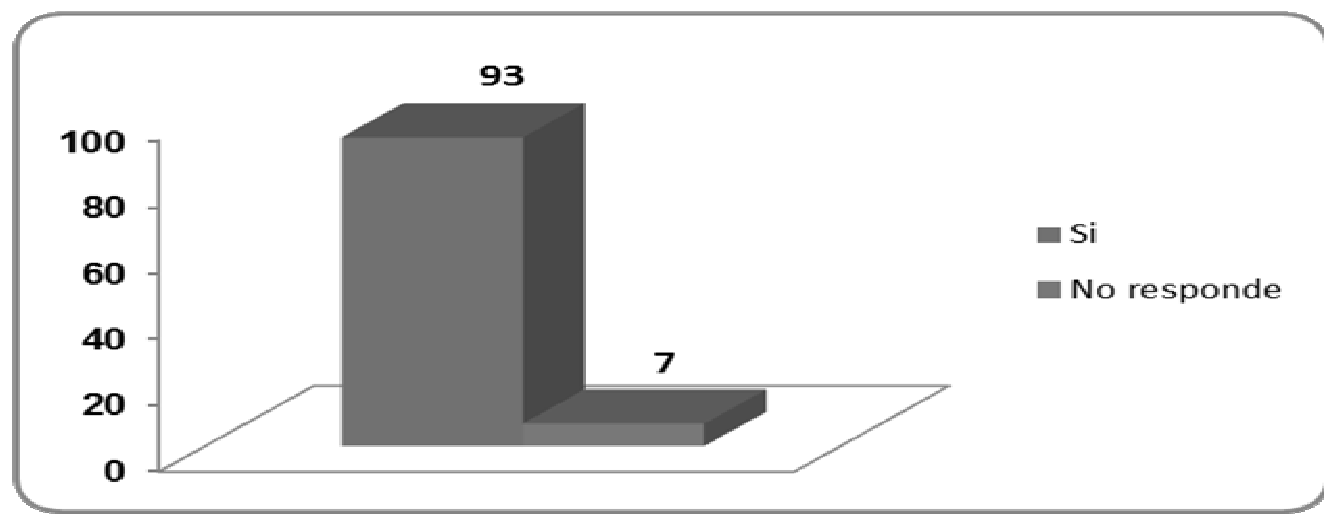

Fuente: Elaboración propia

En la Gráfica 2. Percepción sobre las intervenciones socioambientales realizadas a Julio de 2015, se visualiza la opinión cualitativa que tienen las familias sobre las intervenciones socioambientales. El 35\% las considera excelentes, el $47 \%$ buenas, el $10 \%$ regulares y el $7 \%$ malas, en términos generales una percepción positiva para un $82 \%$ de la población encuestada.

Gráfica 2. Percepción sobre las intervenciones socioambientales realizadas a Julio de 2015

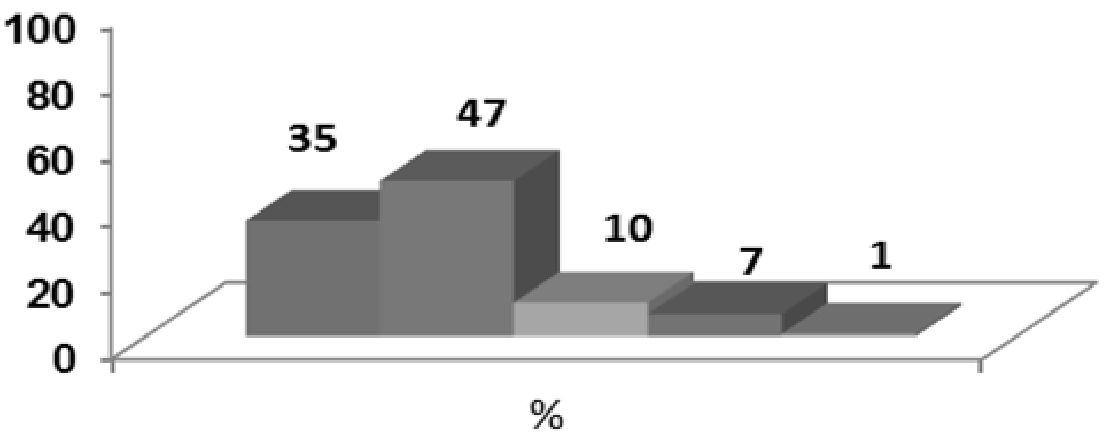

Excelentes $\square$ Buenas $\square$ Regulares $\square$ Malas $\square$ No responde 
En la Gráfica 3. Percepción sobre el mejoramiento de la calidad de vida de los reasentados y las familias habitantes en el morro por las intervenciones socioambientales (Julio de 2015), un $77 \%$ de los encuestados consideran que las intervenciones socioambientales inciden en mejores condiciones de calidad de vida y un $22 \%$ considera no han mejorado sus condiciones en ningún aspecto.

Gráfica 3. Percepción sobre el mejoramiento de la calidad de vida de los reasentados y las familias habitantes en el morro por las intervenciones socioambientales (Julio de 2015)

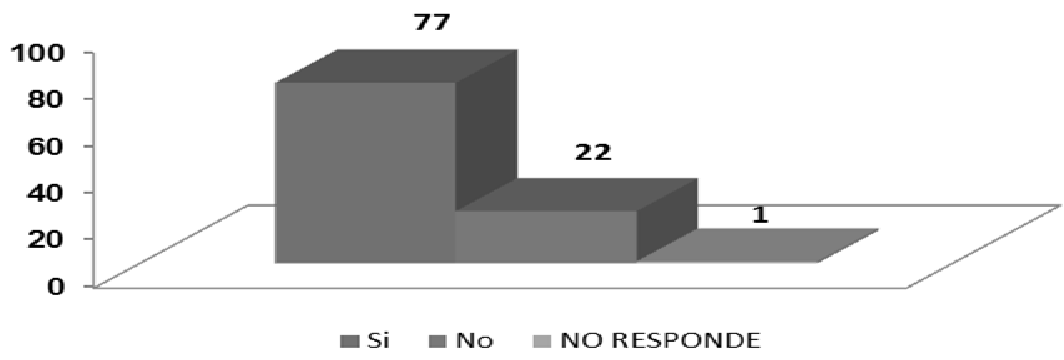

Fuente: Elaboración propia

En el gráfico 4 se relaciona que un $62 \%$ de las familias consideran que se les ha mantenido informados acerca de los avances de las intervenciones socioambientales por parte las instituciones y responsables de su ejecución, no obstante un 34\% aducen no haber recibido información al respecto y un 3\% no opina al respecto.

Gráfica 4. Percepción sobre la socialización de los avances de las intervenciones socioambientales a la comunidad (Julio de 2015)

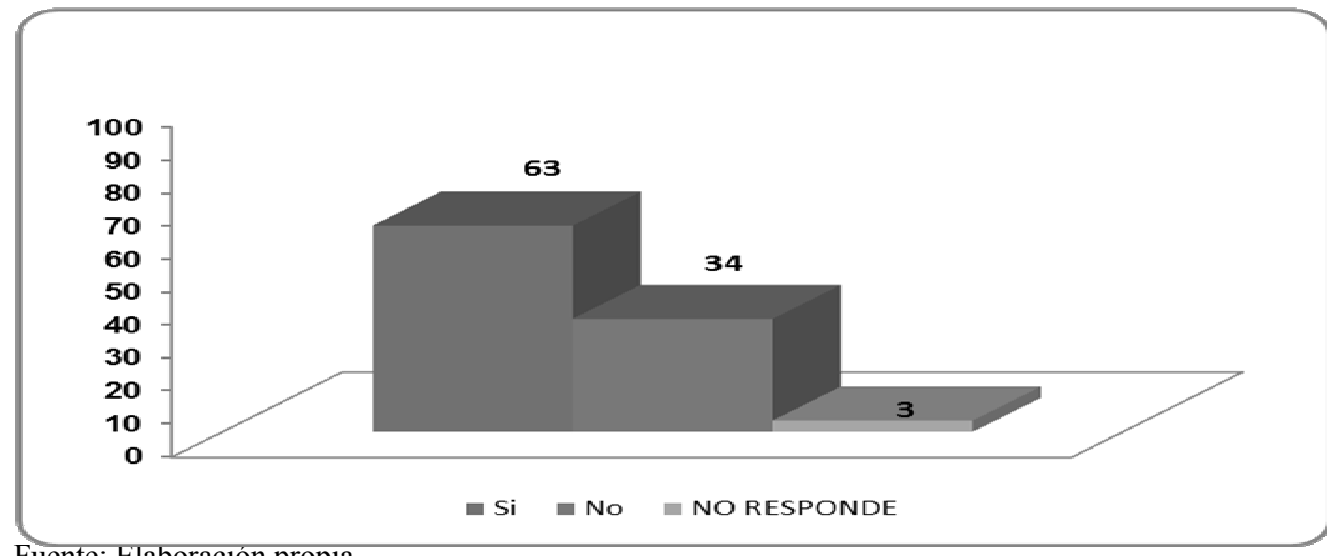

Fuente: Elaboración propia 
Tal y como se recoge en el gráfico 5 , un $60 \%$ de las familias encuestadas consideran la semana de Moravia como un espacio indicado para difundir y dar a conocer los avances de las intervenciones de trasformación socioambiental adelantadas en el morro de Moravia, a diferencia de un 38\% opina no considerar un evento como un canal propicio para la divulgación de los avances de trasformación de su territorio, y un $2 \%$ que se abstuvo de responder.

Gráfica 5. Percepción sobre el evento "Semana de Morovia" como estrategia de divulgación de los avances de las intervenciones de transformación socioambiental en el Morro de Moravia (Julio de 2015)

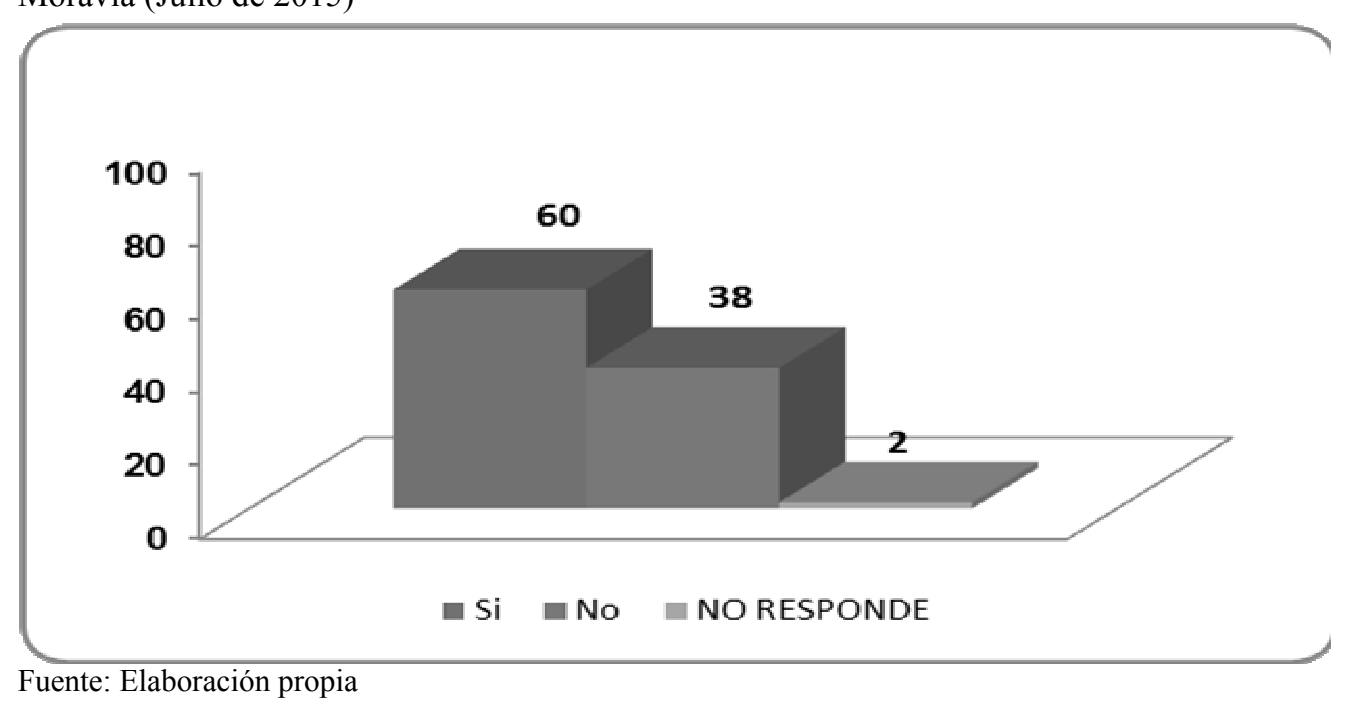

En el gráfico 6, los resultados reflejan la percepción que tienen las familias frente al papel desempeñado por las instituciones (la Alcaldía de Medellín, el Tecnológico de Antioquia, la Universidad de Antioquia, el Jardín Botánico, el Área Metropolitana del Valle de Aburrá, la Universidad Politécnica de Cataluña y la Universidad Pontificia Bolivariana) que han liderado y participado dentro de las intervenciones de transformación socioambiental del morro.

El 34\% de las familias califican el trabajo llevado a cabo por las instituciones como excelente, con buena un $46 \%$, un $10 \%$ con una gestión regular, un $7 \%$ la consideran mala y un $3 \%$ se reservó opinar al respecto. 
Gráfica 6. Calificación del trabajo realizado por las instituciones vinculadas con las intervenciones socioambientales del Morro de Moravia (Julio de 2015)

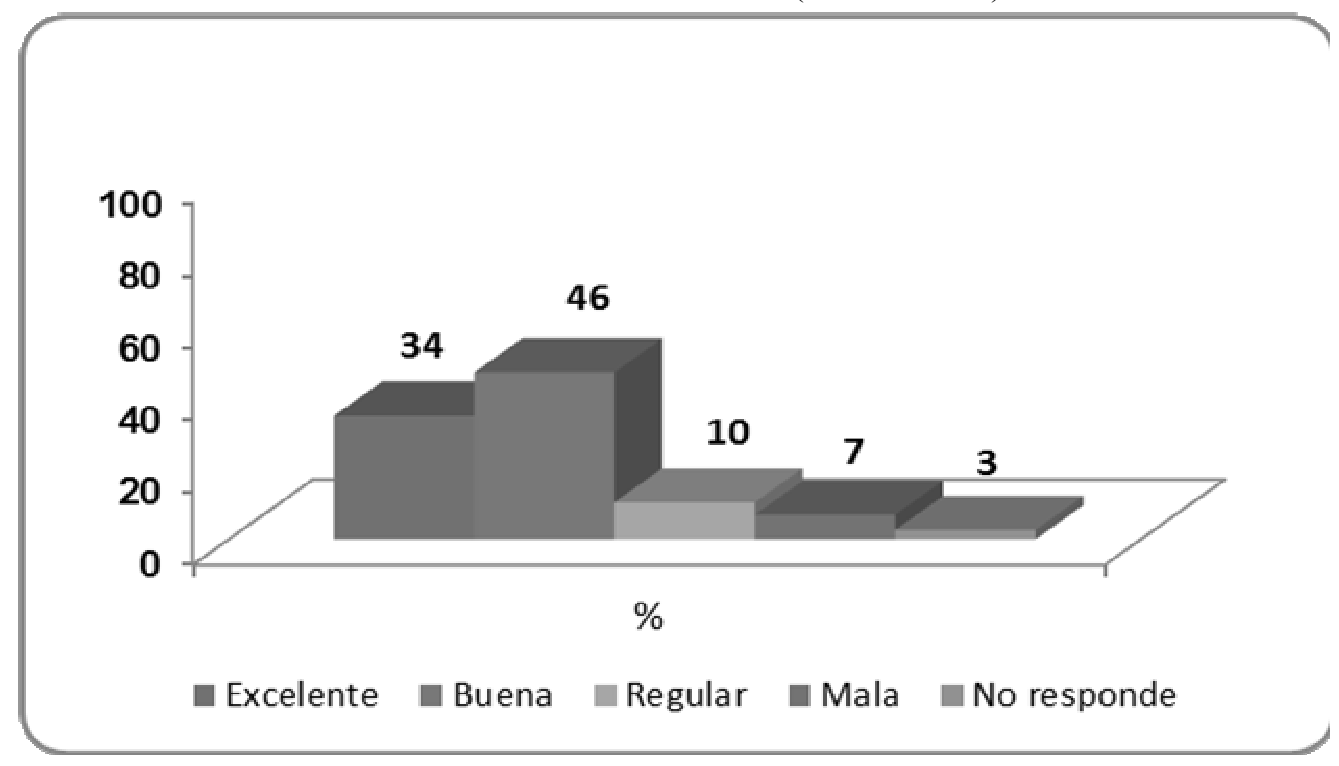

Fuente: Elaboración propia

Al realizar la búsqueda de estudios anteriores que indagaran sobre la percepción de las familias con relación a las intervenciones realizadas en el Morro de Moravia se encontró que en agosto de 2013 en la evaluación de un evento institucional del Tecnológico de Antioquia - Institución Universitaria, se aplicó a 35 líderes y lideresas una encuesta que incluyó dos preguntas que permiten ver tendencias de la percepción de la comunidad frente a las intervenciones realizadas, la primera preguntaba sobre la percepción de los líderes y lideresas de Moravia sobre las intervenciones socioambientales realizadas a esa fecha, y la segunda cuál era lo opinión de los líderes en relación al mejoramiento de sus condiciones de calidad de vida con la ejecución de las respectivas intervenciones (Ver Gráfica 7. Percepción de líderes y lideresas de Moravia sobre las intervenciones socioambientales realizadas a agosto de 2013.

En la Gráfica 7, se encontró que un 63\% de los líderes y lideresas de Moravia consideraban como excelentes las intervenciones socioambientales desarrolladas en el sector de El Morro, un 26\% las cataloga como buenas, mientras un 6\% opinaba que habían sido regulares, quedando un $6 \%$ que no opinaba al respecto. 
Gráfica 7. Percepción de líderes y lideresas de Moravia sobre las intervenciones socioambientales realizadas a agosto de 2013.

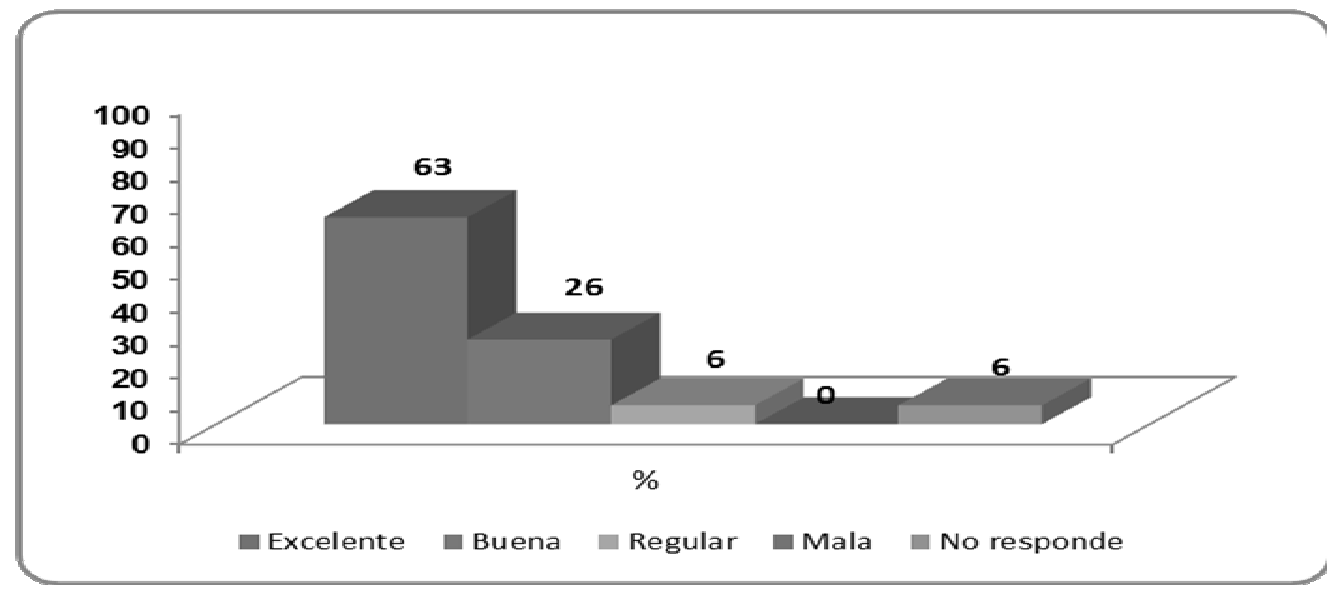

Fuente: Elaboración propia.

Con relación a la percepción que tienen los líderes y lideresas de cómo han mejorado sus condiciones de calidad de vida a partir de las intervenciones llevadas a cabo en el morro de Moravia a agosto de 2013 (Ver Gráfica 8), los resultados mostraban que el $83 \%$ del total de líderes encuestados opinaban que sus condiciones de calidad de vida habían mejorado, un $14 \%$ no consideraban que hayan aportado en el mejoramiento de su calidad de vida, y el $3 \%$ restante no responde.

Gráfica 8. Percepción de líderes y lideresas de Moravia sobre mejoramiento en su calidad de vida por las intercenciones socioambientales realizadas en El Morro a agosto de 2013.

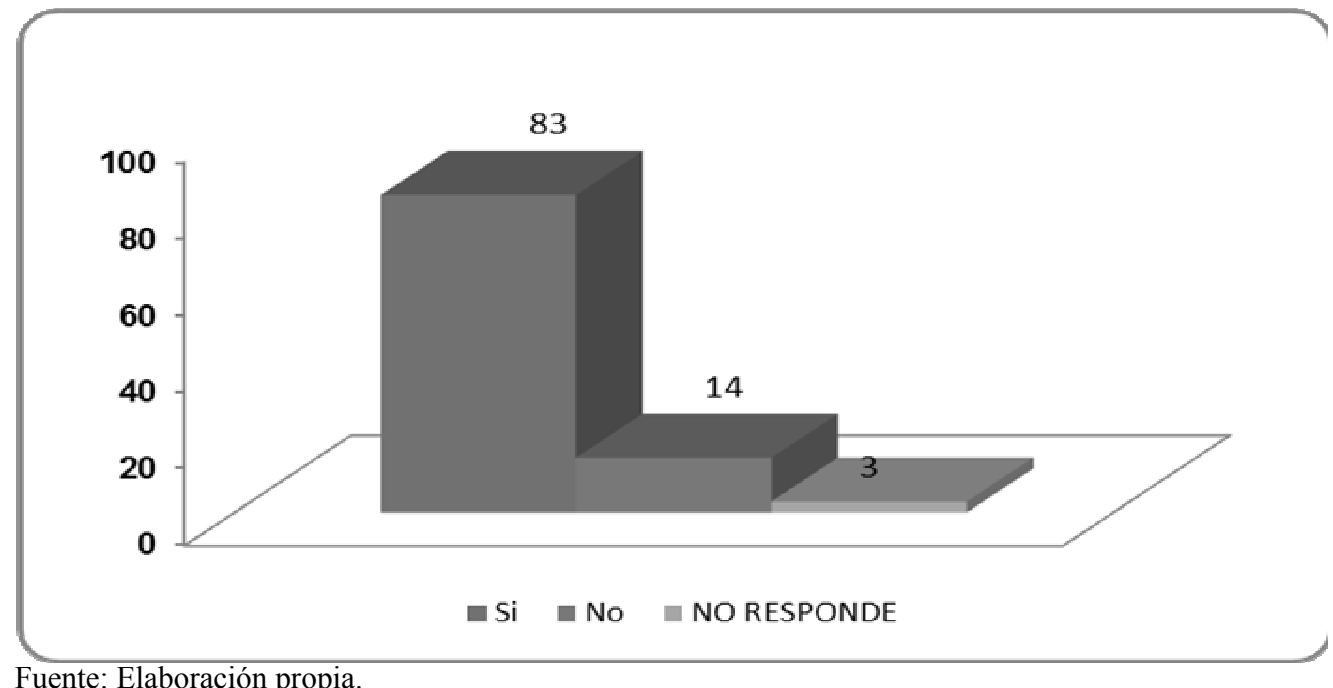

Fuente: Elaboración propia. 


\subsection{Discusión y análisis de resultados}

En la encuesta realizada en el 2013, a líderes y lideresas, el 63\% cataloga las intervenciones "excelentes", y un 26\% "buenas"; es decir, un $89 \%$ de percepción positiva (Gráfica 7), en la encuesta del 2015 donde se incluye tanto la población reasentada como la que habita el morro, la percepción positiva es del 82\% (Gráfica 2).

Considerando, de manera general, los resultados obtenidos, se puede concluir que más del $82 \%$ de las familias valoran de manera positiva las intervenciones de transformación ambiental del Morro de Moravia, contrario a un $18 \%$ que no están satisfechas con las intervenciones, o están en desacuerdo, básicamente, porque manifiestan que los recursos que están invirtiendo en las adecuaciones deberían destinarlos al mejoramiento de vivienda, situación que resulta compleja, puesto que el Morro de Moravia como ya se ha mencionado en esta investigación, es un sitio que presenta alto riesgo por los altos contenidos de metales pesados, posible emisión de gases (condiciones atmosféricas que no se han monitoreado en los últimos años) y a la inestabilidad geológica que su misma composición conlleva.

Frente a la opinión de percepción en el mejoramiento de la calidad de vida de las familias del morro, como consecuencia de las intervenciones socioambientales, en primera instancia, se aclara que sería improcedente comparar los años 2013 y 2015 con la información que se tiene disponible, debido a que la población objetivo no fue la misma; sin embargo, es posible analizar tendencias de percepción. Es evidente que tanto el 2013 como el 2015 muestran que el 83\% y 77\%, respectivamente, opinan haber mejorado sus condiciones de calidad de vida con las intervenciones socioambientales, en contraposición con el $14 \%$ del 2013, y el $22 \%$ del 2015 , que manifestaron no percibir ninguna mejora en sus condiciones de calidad de vida, producto de las intervenciones llevadas a cabo en el Morro de Moravia.

$\mathrm{Al}$ indagar en la población objetivo, sobre el mejoramiento de sus condiciones de calidad de vida, se pueden extractar, de manera general, las siguientes respuestas textuales:

\begin{tabular}{|l|l|l|}
\hline $\begin{array}{l}\text { Sí se han mejorado las condiciones de } \\
\text { calidad de vida, porque: }\end{array}$ & No se han mejorado las condiciones de calidad de \\
vida, porque:
\end{tabular}




\begin{tabular}{|l|l|}
\hline $\begin{array}{l}\text { Sí se han mejorado las condiciones de } \\
\text { calidad de vida, porque: }\end{array}$ & $\begin{array}{c}\text { No se han mejorado las condiciones de calidad de } \\
\text { vida, porque: }\end{array}$ \\
\hline - Se intervienen puntos críticos de & \\
acumulación de basuras & \\
- Se perciben cambios positivos en las & \\
personas & \\
La gente ha dejado de vernos como un & \\
basurero & \\
- Menos riesgos de enfermedades & \\
Han desaparecido y/o disminuido & \\
roedores y olores desagradables & \\
\hline
\end{tabular}

Retomando las respuestas de los encuestados, sus argumentos y el porcentaje asignado a la favorabilidad de si tienen mejores condiciones de calidad de vida, y teniendo en cuenta el planteamiento de Ángel (2003), es viable afirmar que con las intervenciones se ha obtenido un beneficio en la calidad de vida de quienes tienen relación directa con los sitios intervenidos en el Morro de Moravia, por contar con un lugar con mayor espacio público, menor contaminación y condiciones menos severas de afectación a la salud, sumado lo anterior a la oportunidad de empleo que se ha generado, a más de los procesos formativos para consolidar unidades productivas que posibilitan que la comunidad se empodere de las intervenciones.

Pese a tales beneficios, los esfuerzos deben continuar, otorgando relevancia a aspectos sociales como: reasentamiento digno a la población que habita actualmente el morro, y fortalecimiento de la educación y la participación, como elementos claves para la transformación (Morató et al., 2012).

Igual importancia tienen las respuestas de los encuestados que manifiestan que «no se han mejorado las condiciones de calidad de vida». En estas respuestas se destacan aspectos de problemáticas sociales que deben convertirse en reto de sustentabilidad. Para ilustrar por ejemplo las necesidades básicas aún insatisfechas; la percepción ausencia de asignación de recursos de manera equitativa, por ejemplo, para pensar en viviendas dignas antes que continuar con los jardines. Resalta la necesidad de reforzar en los programas de educación y capacitación. Respecto de la cultura del buen manejo de residuos sólidos (relacionado con la «basura» que «la gente sigue botando»); es decir, el reto de futuros proyectos - para intervenciones en Moravia o en cualquier sector- debe reforzar o implementar un diseño adecuado de programas de gestión social que permitan modificar el paisaje y las condiciones físicas de la zona, y así generar un impacto positivo, a diferentes escalas de percepción, entre toda la comunidad.

En relación con la percepción que tiene la población sobre lo informada que se le ha mantenido, de las intervenciones socioambientales del Morro de Moravia, un 62\% de las familias considera que las instituciones y responsables de su ejecución, las ha mantenido informada acerca de los avances de las intervenciones socioambientales; un 34\% de familias afirma no haber recibido información al respecto; y un 3\% no opina acerca de este interrogante. 
Ahora bien, si lo anterior se contrasta con los resultados presentados en la Percepción sobre el evento Semana de Moravia como estrategia de divulgación de los avances de las intervenciones de transformación socioambiental en el Morro de Moravia (Julio de 2015) - un 60\% considera que la Semana de Moravia ha sido un espacio adecuado para difundir y dar a conocer los avances de las intervenciones de trasformación socioambiental adelantadas, a diferencia de un $38 \%$ que no considera el evento como un canal propicio para la divulgación de los avances de trasformación de su territorio y un $2 \%$ se abstuvo de responder.

En este sentido, se resalta la coherencia entre los resultados obtenidos, puesto que un $60 \%$ de las familias se consideran informadas de los avances de las intervenciones, a través del evento ya mencionado; o sea que se trata de un canal importante para la divulgación de los avances. Sin embargo, es claro que esto no es suficiente, por tanto, se requieren de otras alternativas para propiciar y motivar la participación comunitaria.

Un beneficio visible es la conformación de grupos organizados que han surgido a partir de las intervenciones realizadas en el Morro de Moravia. Es el caso de la Corporación de Jardineras y Jardineros de Moravia (Cojardicom), antes denominada Grupo de Jardines comunitarias de Moravia (GJCM), creada en 2010, cuya iniciativa de participación se ha convertido en toda una innovación social, gracias a que se consolida para capacitar y formar a mujeres en el tema de jardinería, de una manera integral, desde el aspecto ambiental, ecológico, social y financiero, posibilitándoles ir forjando su propio negocio para hacerse a un empleo digno, acceder al mercado y contar con recursos para aportar o, en muchos casos, cubrir el sostenimiento total de sus familias, porque en su mayoría son madres cabeza de hogar.

Gracias a la experiencia exitosa de Cojardicom, se crea en 2015 un grupo de Jardines Unidos de Moravia (Jarum), que con catorce integrantes busca consolidarse como una empresa que presta servicios de jardinería.

Estos grupos son el producto de la integración y participación comunitaria que, gracias al apoyo de las diferentes instituciones, del orden local e internacional, logran una gestión ambiental integral que favorece la cohesión social de los distintos actores comunitarios y el cumplimiento de los objetivos de la transformación ambiental, mediante el desarrollo de acciones para la cooperación, la cogestión y la coordinación interinstitucional, tanto para la planificación territorial, la atención y estabilidad social en comunidades marginadas, como para la eliminación de los conflictos ambientales, en el ámbito local y regional (Minotta, 2012).

Un beneficio y fortaleza, producto de las intervenciones socioambientales, es la sinergia entre instituciones públicas y privadas, la academia, la cooperación internacional, así como la participación de los actores locales en el proceso de transformación socioambiental de Moravia. Esta gestión se puede ver reflejada en los resultados obtenidos que se presentan en la Calificación del trabajo realizado por las instituciones vinculadas con las intervenciones sociambientales del Morro de Moravia (Julio de 2015) en donde la percepción de las familias encuestadas para instituciones como: la Alcaldía de Medellín, el Tecnológico de Antioquia, la Universidad de 
Antioquia, el Jardín Botánico, Isvimed, el Área Metropolitana del Valle de Aburrá, la Universidad Politécnica de Cataluña y la Universidad Pontificia Bolivariana, es de una calificación positiva del $80 \%$ (entre excelente y buena), mientras un $10 \%$ la valoran como regular, un 7\% la consideran mala y un 3\% se reservó su opinión.

Es preciso aclarar que de los resultados obtenidos, las instituciones que más visualizan los encuestados como participantes activos de las intervenciones son, en su orden, el Jardín Botánico, el Tecnológico de Antioquia, la Alcaldía de Medellín y la Universidad de Antioquia, lo cual puede obedecer a que han sido quienes contratan el personal de jardinería, lo cual genera mayor recordación entre las familias que ven en esta labor una oportunidad y quizás único ingreso económico para sus hogares.

Desde el punto de vista fisicobiótico, a través de la investigación se advierte la presencia de metales pesados en el suelo; de ahí la necesidad de continuar implementando parcelas de fitorremediación, junto con la implementación de monitoreos regulares que permitan percatarse de los cambios en las concentraciones de los elementos que por su presencia constituyen un riesgo, con la posibilidad de ocasionar contaminación en el entorno. El suelo antroposol del morro está constituido, básicamente, por residuos que contienen altas concentraciones de metales pesados. Aún se debe reforzar el proceso de sintetizar de los mismos.

Los indicadores de ocupación de áreas y densidad demográfica se pueden categorizar como exitosos; en la cartografía se puede evidenciar la evolución a través de los proyectos de reasentamiento realizados; el uso residencial cedió paso al paisajismo, los jardines para biorremediación y fitorremediación e invernaderos. Esto significa que un $87 \%$ marca el cambio de uso residencial a otros usos. Igualmente, en la densidad demográfica del morro ya no se observa una mayoría en asentamientos humanos; ya se puede hablar de una minoría de seres humanos viviendo en condiciones de riesgo. En cuanto a la densidad, al 2014 estaba en $0,119 \mathrm{hab} / \mathrm{m} 2$. Por otra parte, el indicador de comportamiento de la población relativa al porcentaje de reasentamiento, teniendo en cuenta la población proyectada a reasentar, y la población en el 2014 en el morro, este arroja un resultado exitoso, pues registra un $91,6 \%$.

\section{Conclusiones}

Desde la óptica de las familias que habitan el Morro de Moravia o que fueron reasentadas en el mismo barrio, su percepción acerca de las intervenciones socioambientales desarrolladas en la zona es positiva. De hecho, el proceso ha sido acogido por más de un $80 \%$ de las familias, pues han visto mejoradas sus condiciones de calidad de vida, en aspectos como generación de empleo, mejores espacios públicos, disminución de la contaminación, fortalecimiento en la seguridad de la zona, sumado a la consolidación de procesos formativos para apuntalar unidades productivas que permitan que la comunidad se empodere de las intervenciones. 
El uso del análisis cartográfico permitió visualizar de manera multitemporal los cambios en el espacio, observando la transición y el cambio representativo; es una forma de ver la evolución en el tiempo, en una escala constante que hace visible el éxito de las intervenciones para la transformación física y demográfica del morro de Moravia.

A lo largo de la investigación se observa un cambio positivo en los proyectos de reasentamiento en relación con la ocupación del territorio, por lo que se percibe el cambio en el uso del suelo de inclinación residencial para viviendas de personas de bajos recursos a un terreno que se encuentra en proceso de rehabilitación, buscando minimizar la vulnerabilidad de las personas por exposición a diferentes riesgos. Esto se pudo observar en los indicadores de ocupación de áreas, densidad de población, porcentaje de reasentamiento de la población.

\section{Bibliografía}

Agencia española de Cooperación \& Grupo Tragsa, 2012. La transformación del vertedero de La Chureca, Proyecto de Desarrollo Integral del Barrio de Acahualinca - Managua, Nicaragua. Recuperado el 18 abril de 2015 de http://www.aecid.es/galerias/noticias/descargas/2013/La_Transformacixn_del_Vertedero_ de_La_Chureca.pdf.

Ángel, A. (2003). La Diosa Némesis. Desarrollo sostenible o cambio cultural. Cali: Corporación Universitaria Autónoma de Occidente.

Berdegué, J., Ocampo, A., \& Escobar, G. (2007). Sistematización de experiencias locales de desarrollo agrícola y rural. PREVAL Y FIDAMERICA. Recuperado de: http://www.fidamerica.org/admin/docdescargas/centrodoc/centrodoc_178.pdf.

Corellano, F. (2014). El medio ambiente urbano: interfase naturaleza cultura. Recuperado de http://www-etsav.upc.es/personals/monclus/cursos/1202.htm

Fabregat, C., Casabó, J., Fabado, J., Soler, J.X., Ranz, J. \& Navarro, F. 2011. Habitats cartography of the Valencian Community: a GIS-based tool for the management and conservation of Natura 2000 vegetation types in eastern Spain.

Garrido, E. (2010). Los nuevos principios del urbanismo y diario de un hipermoderno de Francois Ascher. Ángulo Recto. Revista de estudios sobre la ciudad como espacio plural. Recuperado de: http://revistas.ucm.es/index.php/ANRE/article/viewFile/ANRE1010220163A/6094

Minotta, W. (2012). La Participación Ciudadana, un reto en la Gestión Ambiental. Experiencias significativas de participación ciudadana y conocimiento tradicional en la gestión ambiental (pp.12-16). Recuperado de http://www.minambiente.gov.co/documentos/DocumentosBiodiversidad/publicacio nes/170412_boletin_gestion_ambiental.pdf

Morató, J., Escribano, B., Bestraten S., Hormias E., Gallegos, A., Ortiz, A., \& Verdú, A. (2012). Reciclar ciudad: repensar la transformación hacia una gestión sostenible del 
territorio. Sostenibilidad, Tecnología y Humanismo. Cátedra UNESCO de Sostenibilitat, Universitat Politècnica de Catalunya, 83-94.

Organización de las Naciones Unidas, (2012). Estado de las Ciudades de América Latina y el Caribe 2012, Rumbo a una nueva transición Urbana, Rio de Janeiro: Programa de las Naciones Unidas para los Asentamientos Humanos. ONU-Habitat. Consultado el 24 de mayo de 2015. Recuperado de:

http://mirror.unhabitat.org/pmss/listItemDetails.aspx?publicationID=3380\&AspxAutoDete ctCookieSupport AspxAutoDetectCookieSupport=1

Salazar, M. (2003). Evaluación de la restauración del paisaje en el Canton de Hojancha, Guanacaste, Costa Rica. Tesis Mag. Sc. Turrialba, CR, CATIE. 98 p. Recursos Naturales y Ambiente, (45).

\section{Agradecimientos}

A Gerardo José López por sus servicios como profesional SIG. A la Secretaria del Medio Ambiente de la Alcaldía de Medellín, que financia el proyecto "Moravia florece para la vida" por facilitar información obtenida en sus procesos de intervención y ponerla a disposición para el análisis. A la gerencia del macroproyecto de Moravia por permitirnos acceder a la información de Moravia y apoyar en las gestiones de articulación y consecución de información. Al grupo de investigación INTEGRA, asociado a la facultad de Ingeniería dentro del programa Ingeniería Ambiental en el Tecnológico de Antioquia, por suministrar información valiosa de sus investigaciones desarrolladas en el Morro de Moravia. Al director de la Cátedra UNESCO de Sostenibilitat de la Universidad Politécnica de Catalunya: Dr Jordi Morató por los valiosos aportes, sugerencias y recomendaciones para el desarrollo de este proyecto. Al grupo UNESCOSOST Colombia por toda la asesoría brindada. A todo el equipo de trabajo del proyecto "Moravia florece para la vida" por brindarnos su apoyo dentro de las competencias profesionales y personales. A la Dra. Adriana González Osorio del Departamento Administrativo de Planeación de Medellín, por facilitar la ruta de acceso a la información publicada en los boletines de información demográfica. Al grupo de Jardineros Comunitarios de Moravia (COJARDICOM) y al grupo Jardines Unidos de Moravia (JARUM) por su gran apoyo en las labores realizadas en campo. A la comunidad Moravita por disponer de su tiempo para dar respuesta a los interrogantes surgidos en el desarrollo de este proyecto de investigación. A la Universidad de Manizales, la Universidad de Antioquia, la Universidad Santo Tomás, El Tecnológico de Antioquia - Institución Universitaria, por las bases para la estructuración de este ejercicio interdisciplinario gracias a la formación recibida en estas prestigiosas instituciones. A los ingenieros Joe Sánchez, Carlos Dávila y Mauricio Pajoy y el Tecnólogo Santiago Carvajal por su apoyo y acompañamiento en el trabajo de campo. 